\title{
Transfusions in Danish medical patients: adherence to guidelines and effect of interventions
}

This article was published in the following Dove Press journal: International Journal of Clinical Transfusion Medicine

\author{
Lars Larsen Stubbe \\ Teglbjærg' \\ Mie Topholm Bruun ${ }^{2}$ \\ Kjell Einar Titlestad ${ }^{2}$ \\ 'Department of Internal Medicine \\ and Acute Medicine, OUH Svendborg \\ Hospital, Svendborg, ${ }^{2}$ Department of \\ Clinical Immunology, OUH Odense \\ University Hospital, Odense, Denmark
}

Correspondence: Lars Larsen Stubbe Teglbjærg

Department of Medicine M/FAM, OUH Svendborg Hospital, Baagøes Alle 15, DK-5700 Svendborg, Denmark

Tel +452462 9758

Fax +45 63202229

Email lars.stubbe.teglbjaerg@rsyd.dk
Introduction: The use of blood components per inhabitant in Denmark has for many years been among the highest in the world. The purpose of the present study was to study the indications for red cell transfusions, and the adherence to the Danish National guidelines, in a group of Danish medical patients.

Methods: This study was a retrospective, observational study on blood transfusions given at a department of internal medicine. Audit standards were developed from national guidelines. A local campaign consisting of questionnaires, monthly oral status presentations, motivational policy posters, educational sessions, feedback intervention letters, and a compulsory e-learning course was carried out.

Results: During 2015, a marked two-third decrease in blood use was observed. In the study period, overall $48 \%$ had a recorded valid indication, but only few had anemia-specific symptoms. The combination of a valid indication and a one-unit strategy was only recorded in $31 \%$ of transfusions. Overtransfusion occurred frequently.

Conclusion: The transfusion practice recorded in this study was mainly in accordance with present guidelines, and reflected the high quality of care given. However, both valid indications and informed consent were lacking in a substantial number of the transfusion episodes. This should be a priority for further action. The study indicates that a combination of focus and educational interventions makes it possible to achieve a considerable reduction in red blood cell transfusions in a mixed medical population.

Keywords: red blood cells, transfusion, single-unit, guidelines, intervention

\section{Introduction}

The use of blood components per inhabitant in Denmark was for many years the highest in the world. ${ }^{1}$ As a consequence, the Danish Health Authority published a restrictive national guideline on blood transfusion in 2007, where one of the key elements was to reduce the high consumption of donor blood in Denmark. ${ }^{2}$ The use of blood has indeed declined since 2007, as stated in reports from the Danish Transfusion Database ${ }^{3}$ and from the Danish Health Authority. ${ }^{4}$ A revision of the guideline was published in $2015,{ }^{5}$ with recommendations for an even more restrictive transfusion strategy and a one-unit transfusion practice.

Scientific evaluation of transfusion practice has been performed in different surgical and intensive care settings, but studies in the area of internal medicine are sparse. Other studies have shown that overtransfusion is frequent ${ }^{6}$ when the level of post transfusion hemoglobin $(\mathrm{Hb})$ is compared to current guidelines. ${ }^{3}$ This seems to be one of the reasons for the high transfusion rate in Denmark, and our hypothesis was 
that this was due to non-compliance with guidelines. The present study was designed in order to study the indications for red blood cell (RBC) transfusions, and the adherence to transfusion guidelines, in medical patients in a Danish medical population. It is known that interventions can reduce a physician's levels of inappropriate transfusions, but there is not much knowledge concerning interventions on transfusions in internal medicine. ${ }^{7}$ The second aim of our study was to investigate whether targeted education and focus could increase compliance with guidelines.

\section{Materials and methods}

We conducted an observational intervention study with retrospective registration of $\mathrm{RBC}$ transfusions and indications for RBC transfusions.

The study included patients at the Department of Internal Medicine at a Danish hospital, including patients at the emergency department and patients in the outpatient clinic, who received blood transfusions from May 1, 2015 to October 31, 2015. Patients with suspected need of thrombolysis or invasive cardiology were transferred directly to other departments and thus not included in the study. The hospital serves as the primary care hospital for approximately 160,000 citizens. The Department of Internal Medicine received non-selected medical patients, including cardiologic, stroke, and medical patients in need of intensive care. The department also offers an outpatient transfusion service for hematological, oncological, and primary care patients.

Data on indications for transfusion and on compliance with national guidelines were retrieved from questionnaires and from medical records.

Data on blood transfusions were obtained from the transfusion database (ProSang; Databyrån för Informationsbehandling AB, Stockholm, Sweden) at the Department of Clinical Immunology, Odense University Hospital, Odense, Denmark.

A local campaign was launched in the Department of Internal Medicine to influence the decision making of the personnel involved in transfusions.

The campaign included monthly oral presentations of transfusion practice for all doctors, motivational policy posters presenting simplified key elements of the national guidelines, and educational sessions on transfusion practice for both doctors and nurses.

In cases of transfusion decisions that did not comply with the guidelines, standardized feedback letters were given to clinicians.

In parallel, mandatory e-learning courses in transfusion medicine were launched in August 2014 in the Region of Southern Denmark, for medical doctors and nurses respectively.

Changes in transfusion practice were evaluated monthly, in order to generate possible new interventions to enhance and accelerate improvement. As an example, pocket cards with key elements of the guidelines were distributed to all doctors, and a simplified poster solely focusing on transfusion triggers was placed in offices for personnel on duty.

During the study, standardized questionnaires on all transfusion decisions were filled in by the clinician who prescribes the transfusions, including questions on indication for transfusion decisions. Missing questionnaires were filled in by the corresponding author on data extracted from the patient records.

The questionnaire covers the transfusion indications and transfusion triggers specified in the national guidelines. ${ }^{5}$ In brief, the national guidelines recommends a one-unit transfusion strategy for stable, normovolemic adult patients, in an inpatient setting, who do not have clinically significant bleeding.

Patients with clinically significant bleeding are transfused based on individual assessment by the treating clinician.

The following hemoglobin values are suggested trigger values:

- $\mathrm{Hb}<4.3 \mathrm{mmol} / \mathrm{L}$ and/or clinical symptoms of anemia in circulatory stable patient without heart disease.

- $\mathrm{Hb}<5.0 \mathrm{mmol} / \mathrm{L}$ and chronic heart disease and/or clinical symptoms of anemia in circulatory stable patient with chronic heart disease.

- $\mathrm{Hb}<5.6 \mathrm{mmol} / \mathrm{L}$ in patients with acute coronary syndrome in ischemic phase or life-threatening bleeding.

The following symptoms were considered specific for anemia: chest pain and/or orthostatic hypotension and/or tachycardia not alleviated by fluid therapy.

For patients with malignant hematological disease, individual transfusion decisions were recommended. A translated version of the questionnaire provided to transfusing physicians is shown in Figure $\mathrm{S} 1$.

The following data were extracted from the medical records:

- Number of patients transfused.

- Number of prescribed red cell transfusions.

- Number of individual transfusion episodes (a transfusion episode starts when a clinical decision of transfusion is made, and ends when the prescribed number of transfusions has been given. Thus, an episode can consist of a single unit transfusion, or transfusions of multiple units with or without reassessment between transfusions). 
- Age and sex.

- Location of transfusion: ward, emergency department, outpatient clinic.

- Pre-transfusion $\mathrm{Hb}$ : $\mathrm{Hb}$ measured less than 24 hours before transfusion and later than any earlier transfusion.

- Post-transfusion $\mathrm{Hb}: \mathrm{Hb}$ measured less than one week after the transfusion, but prior to any later transfusion.

- Charge of the medical doctor prescribing transfusion (i.e. junior doctor or specialist).

To evaluate the variations in transfusion practice, we registered the changes in transfusion episodes as well as changes in the total number of units transfused in the medical department.

Audit was performed by the standards from the national guidelines: Hb level, comorbidity, specific and non-specific symptoms, single or multiple transfusions. ${ }^{5}$

The appropriateness of transfusion was evaluated in a three-step "mini-Delphi” procedure ${ }^{8}$ in which:

- Data of all recorded symptoms, Hb values and recorded individual transfusion thresholds were collected from the electronic medical records.

- Each of the three authors indicated whether the combination of symptoms, $\mathrm{Hb}$ values, and recorded individual transfusion threshold, if applicable, gave sufficient indication for transfusion.

- In case of disagreement, consensus was agreed upon.

The study was approved by the Danish Health Authority, case no. 3-3013-1126/1. The Danish Health Authority granted a waiver of informed consent for this retrospective chart review study where data were anonymized, and no patient identifiable data were stored.

\section{Results}

In the 6-month intervention period, data were available on 125 patients (64 females and 61 males). Seventy-three were inpatients and 52 outpatients. The median age was 80 years (mean 75.5, range 39-99 years). Thirty-two patients had ischemic heart disease and 19 had hematologic disease, and thus had an individual, often higher, threshold for transfusion according to guidelines. ${ }^{5} \mathrm{~A}$ total of $266 \mathrm{RBC}$ units were transfused in 172 transfusion episodes. Of these, 16 were patients with malignant hematological disease, 12 of these fulfilled criteria for transfusion in circulatory stable patients without hematological disease and only 4 patients had an individual transfusion decision. A one-unit strategy was followed in 6
Table I Recorded transfusion indications

\begin{tabular}{lll}
\hline & $\mathbf{n}$ & $\%$ \\
\hline Specific symptoms of anemia* & 7 & $4 \%$ \\
Anemia** + bleeding $^{*}$ & 19 & $11 \%$ \\
Anemia** + unspecific symptoms & 127 & $74 \%$ \\
No symptoms recorded (solely anemia**) & 19 & $11 \%$ \\
\hline Notes: *Chest pain and/or orthostatic hypotension & and/or tachycardia not \\
alleviated by fluid therapy; **Anemia defined as Hb below reference. \\
Abbreviation: Hb, hemoglobin.
\end{tabular}

hematological patients, while 10 had initial prescription of two units of RBC.

Transfusion indications, as established from the patient records and questionnaires, are presented in Table 1.

In $116(67 \%)$ of the transfusion episodes one unit were transfused, and in the remaining 56 episodes (33\%) two or more units were transfused. Assessment of effect between each unit of transfusion was recorded in 15 cases of multiple transfusions.

In $21 \%$ (36 of 172) of the transfusion episodes, pretransfusion $\mathrm{Hb}$ was above the recommended threshold for transfusion according to the national guidelines. In 8 transfusion episodes, two or more units were administered without specific indications and despite hemoglobin level over the recommended threshold for transfusion. A pre-transfusion $\mathrm{Hb}>5.6 \mathrm{mmol} / \mathrm{L}$ was recorded for 14 outpatients and 2 inpatients.

In more than one-third of the cases, it was not possible to clearly decide if transfusions were in accordance with the national guideline. Although 136 episodes were registered with an $\mathrm{Hb}$ below the threshold where transfusion should be considered, only 82 of these had recorded symptoms or other valid indications according to guidelines.

Post transfusion $\mathrm{Hb}$ was available in 75 transfusion episodes, 73 of these were inpatient transfusions. Number of cases of overtransfusion in this subgroup was 10 (13\%), when overtransfusion was defined as post transfusion $\mathrm{Hb}$ of $1.2 \mathrm{mmol} / \mathrm{L}$ higher than the threshold set for that group of patients. ${ }^{6}$ In most inpatient transfusion episodes, it was not possible to determine the charge of the person making the primary transfusion decision, since decisions were made in a team of junior and senior doctors. All transfusion decisions in the outpatient clinic were made by or supervised by a senior specialist.

Only 7 cases of informed consent for transfusion were registered in patient records.

During the 6-month intervention period we observed a decrease in transfusion episodes, as shown in Figure 1, but we did not observe any clear changes in the compliance with 


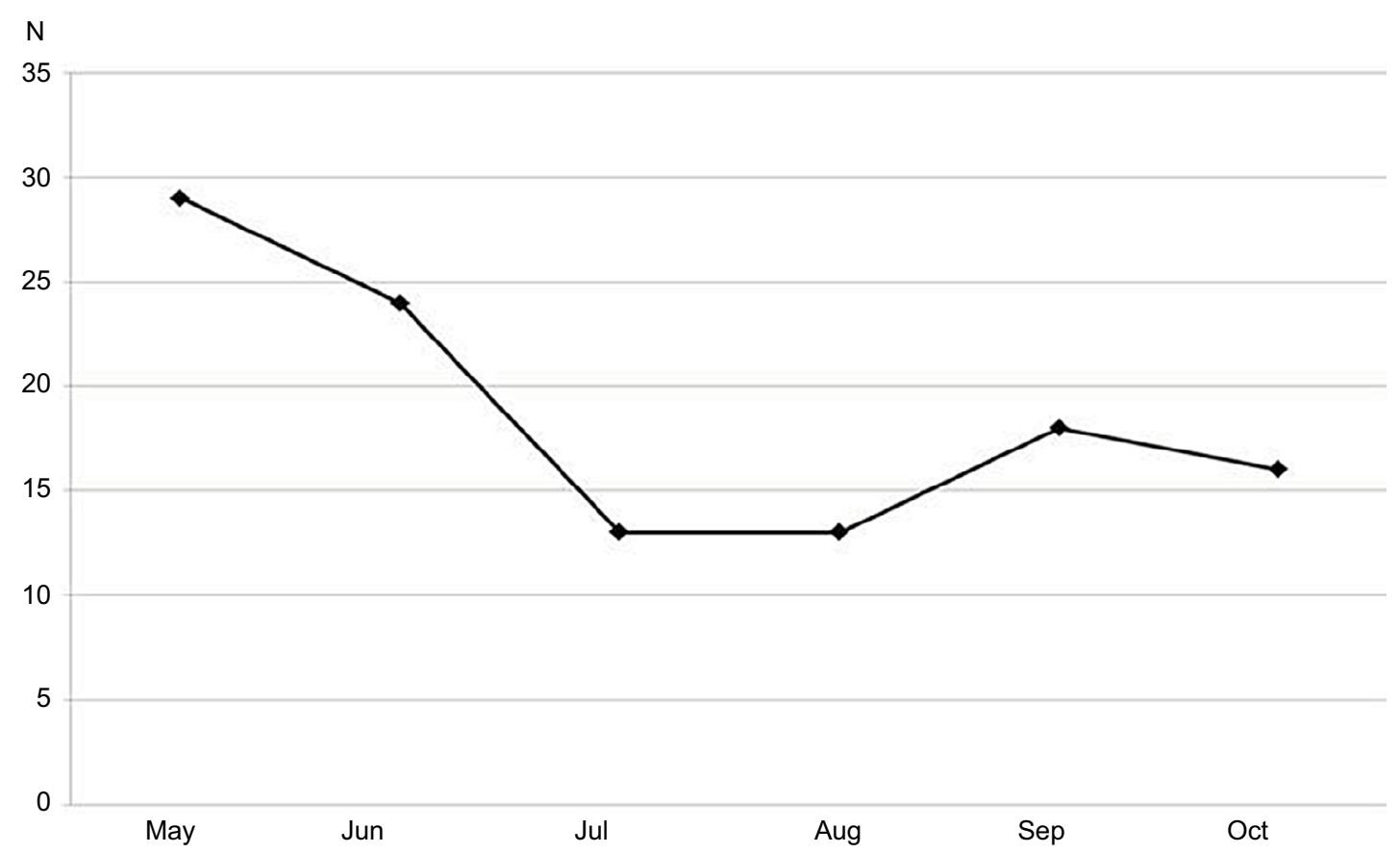

Figure I Number of transfusion episodes during intervention in 2015.

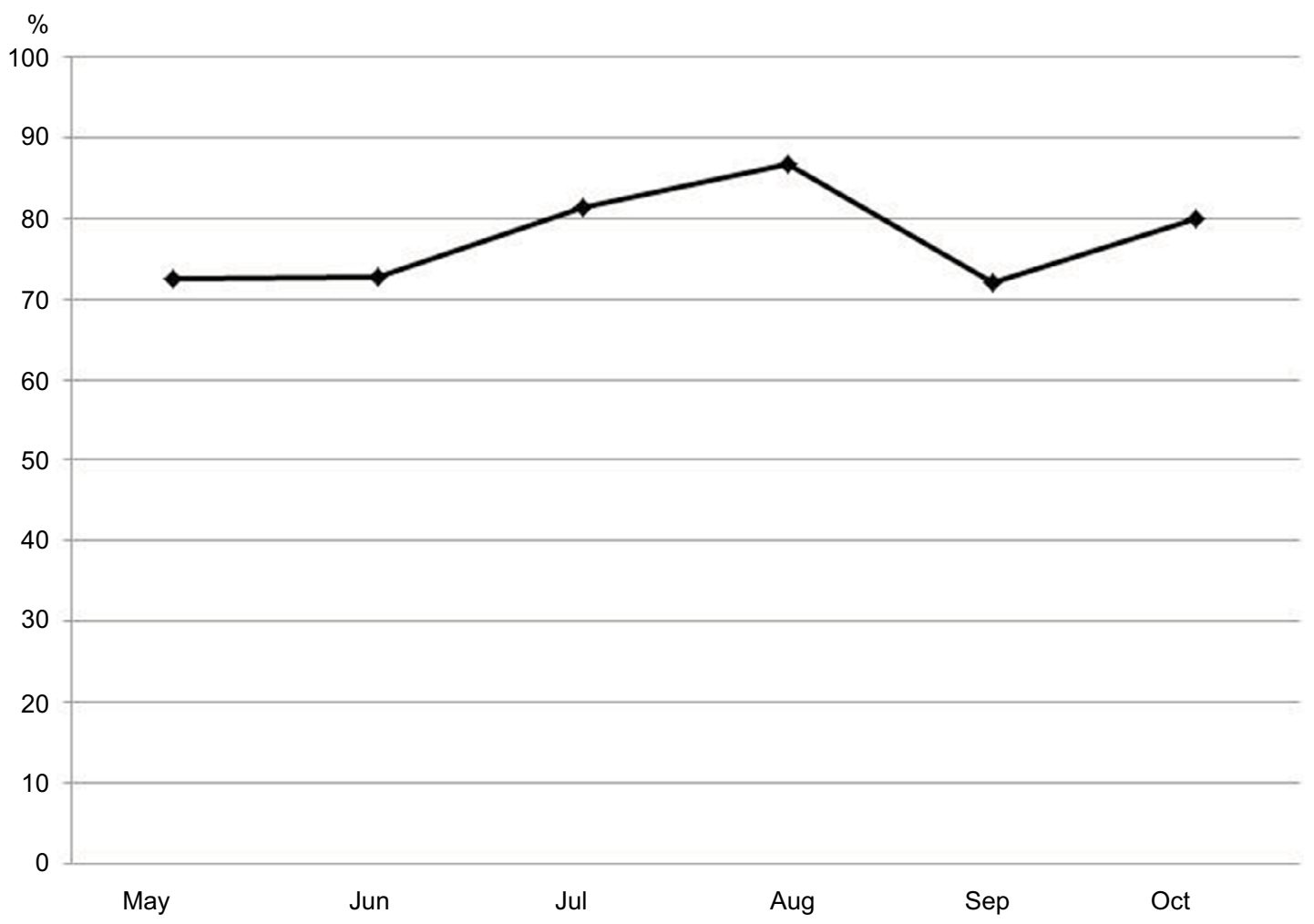

Figure 2 Percentage of transfusion episodes in accordance with guidelines.

transfusion guidelines, as shown in Figure 2. No referrals to the hospital contained information on informed consent, and no systematic recording of transfusion effect on symptoms were observed.
No adverse advents due to lack of transfusion were reported; one serious adverse event (hospitalization for severe respiratory insufficiency following transfusion) was reported in the intervention period. 
During 2015 an overall decrease in blood use in the department was observed (Figure 3). More than a two-third reduction in the use of RBC was observed from the first three months to the last three months of 2015. A reduction was sustained during the last two months of 2015 and through 2016.

\section{Discussion}

The benefits of blood transfusion are not always clear, and the true indication for RBC transfusion in non-bleeding medical patients is unclear. Several guidelines have been published over the years, establishing hemoglobin triggers to optimize transfusion practice. Present guidelines are aimed at balancing the benefit of treating anemia, with the desire to avoid unnecessary transfusions, considering factors related to the patient's clinical status and oxygen needs. A decrease in blood use was already observed in April 2015, before the actual intervention period started.

Simply the presentation of information on the forthcoming intervention might have had a considerable impact. As shown in Figure 3, the large reduction in RBC use observed in spring 2015 is not observed in 2016, indicating that the reduction is not due to seasonal transfusion variations. However, a weakness of our study is that we did not have permission to collect data from patient records for the time before the intervention.

It is noteworthy that only $15 \%$ of the recipients had bleeding or specific symptoms of anemia as indication for transfusion. In our material, guidelines for non-hematological patients were followed for $75 \%$ of patients with malignant hematological disease, but for $63 \%$ a one-unit strategy was not followed. The Danish guidelines do not restrict or support liberal administration of transfusions to patients with malignant hematological disease. It is noted that the number of observations in this group of patients is small.

The rapid decrease in transfusions suggests that blood transfusions not following existing guidelines have been widely used before the intervention. It seems likely that for blood transfusions, the possible benefits are grossly overestimated and the risks are neglected.

The compliance with the national guidelines (Figure 2) did not change substantially during the intervention period. This might be due to information given before the start of the actual intervention period, and there might have been an

No. RBC units

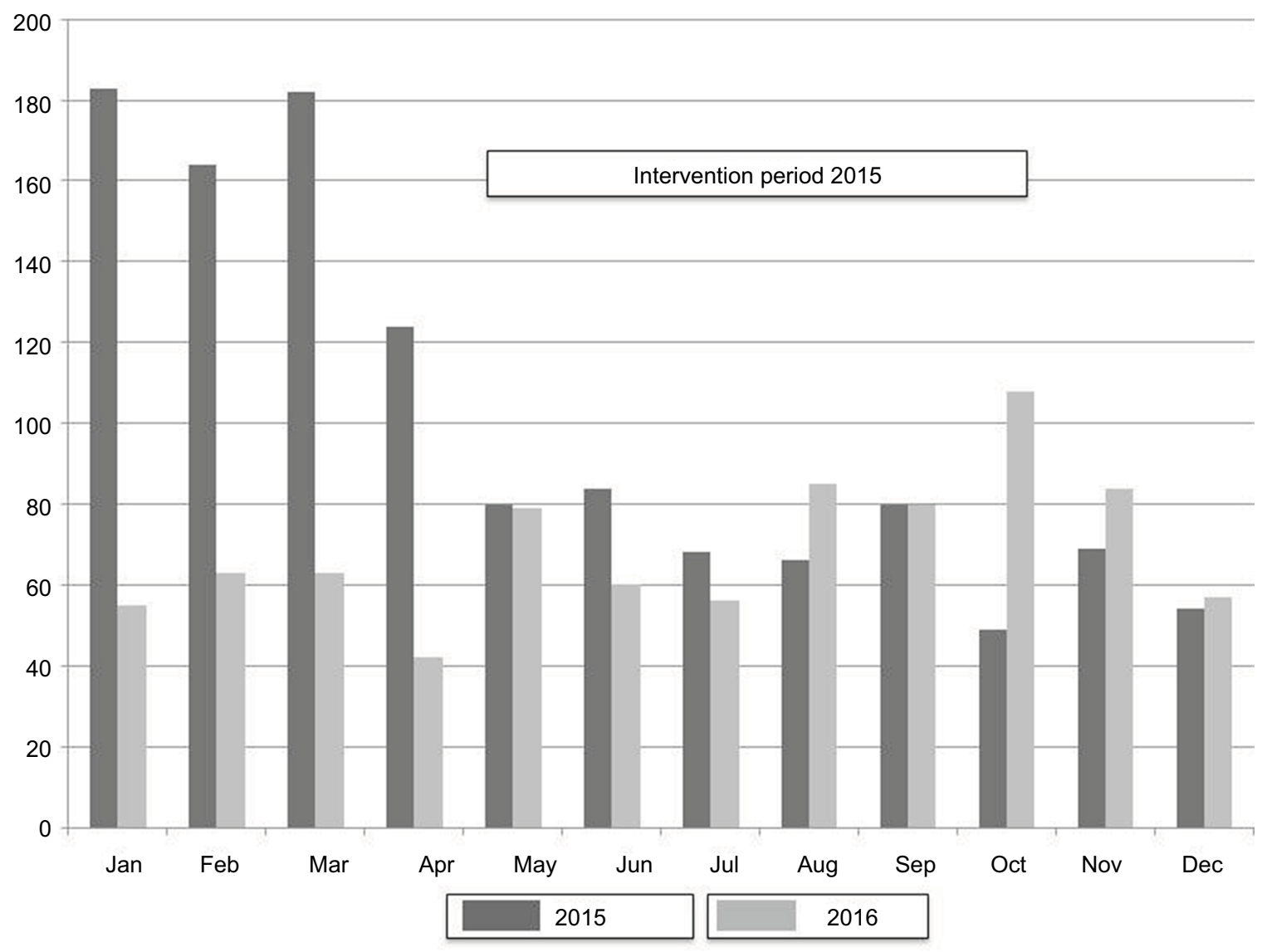

Figure 3 Total use of red blood cells in 2015/2016.

Abbreviation: RBC, red blood cell. 
increase in compliance in parallel with the observed decrease in transfusion rates. However, $20 \%$ of the transfusions given in the last month of the intervention period were not in accordance with the national guidelines. This suggests a potential for further improvement in transfusion practice.

In this study, we used educational interventions to avoid excessive blood transfusions by focusing on compliance with existing guidelines. A recent randomized study documented that present medical practice can be optimized by feedback intervention letters. ${ }^{9}$ We used this tool, but our study was not designed to measure the effect of this in our campaign.

One could speculate that the practice before our interventions reflected the physician's tolerance level for anemia ${ }^{10}$ more than the patient's actual need for transfusion. Learning by imitation, rather than from facts and up-to-date knowledge on risks and benefits of transfusions, seems to have driven previous transfusion practice. The knowledge has been provided as one-way written information, without control of whether the message has been understood and without any feedback to the individual physician.

Informed consent was rarely documented in the medical record, possibly due to the fact that no formal guidelines on obtaining informed consent exist in the department. Although written information on transfusion is available for the patients, this information is not routinely given to the patients at risk of transfusion.

\section{Limitations}

Our study has several limitations, such as the limited number of patients and the retrospective, single-center design. The most important limitation may be recall bias, since information on transfusions was collected retrospectively. The design does not allow determination of the effect of the individual elements of the intervention applied. The initial reduction in transfusions before the intervention suggests that the mere knowledge of a coming intervention might be the most important factor, the so-called Hawthorne effect. ${ }^{11}$ It must be noted that a continuing focus on transfusions has been established in the department as well as in the hospital. It is possible that the Hawthorne effect constitutes an important factor in the maintenance of the reduction in RBC transfusions.

The transfusion practice recorded in this study was mainly in accordance with present guidelines, and reflected the high quality of care given. However, there are still areas of concern. Valid indication was lacking in a substantial number of the transfusion episodes. The mere idea of curing anemia with transfusions seems still common. This might prevent rational decisions and the necessary change of behavior. There is a lack of both a documented indication and recorded informed consent in a considerable number of the transfusions reported in this study. This should be a priority for further action.

Unnecessary transfusions have no benefit for the patients. And although Danish donors are unremunerated volunteers, the associated costs for blood for transfusion are not negligible.

The simple low-cost approach used in this study seems to be effective in implementing evidence-based knowledge into clinical practice, indicating that a dedicated focus in combination with educational intervention makes it possible to achieve a considerable reduction in RBC transfusions in a mixed medical population.

\section{Acknowledgment}

We would like to thank Michael Dall for his contribution with comments and advice and for his enthusiastic support in education and implementation of interventions and guidelines as Head of Department M/FAM in 2015.

\section{Disclosure}

The authors report no conflicts of interest in this work.

\section{References}

1. Titlestad K. Overforbrug af blodkomponenter i Danmark [Overuse of blood components in Denmark]. Available from: http://ugeskriftet. $\mathrm{dk} /$ videnskab/overforbrug-af-blodkomponenter-i-danmark. Accessed January 2, 2018. Danish.

2. Sundhedsstyrelsen. Vejledning om blodtransfusion 2007. [Guidance on blood transfusion 2007]. VEJ nr 10333 af 20/12/2007. 2007. Available from: http://www.dasaim.dk/wp-content/uploads/2014/02/ vejledn_om_blodtransfusion.pdf. Accessed January 2, 2018. Danish.

3. Dansk Transfusionsdatabase. Årsrapport. 2015 [Danish database on Transfusion. Annual Report 2015]. Available from: www.sundhed.dk/ content/cms/13/4713_dtdb_årsrapport-juni-2015.pdf. Accessed January 2, 2018. Danish.

4. Sundhedsstyrelsen. Redegørelse for blodproduktområdet 2014. [Review of blood product area 2014]. 2015. Available from: https://laegemiddelstyrelsen.dk/da/nyheder/2015/ /media/42A88D00EBBF4C B997EB37FF78AEC28F.ashx. Accessed December 13, 2016. Danish.

5. Sundhedsstyrelsen. Vejledning om blodtransfusion 2015. [Guidance on blood transfusion]. VEJ nr 9038 af 15/01/2015. 2015. Available from: https://sundhedsstyrelsen.dk/da/nyheder/2015/ /media/8147748CEC6 140FF9112674B5EF1307B.ashx. Accessed January 2, 2018. Danish.

6. Barr PJ, Donnelly M, Cardwell CR, Parker M, Morris K, Bailie KE. The appropriateness of red blood cell use and the extent of overtransfusion: right decision? Right amount? Transfusion. 2011;51(8):1684-1694.

7. Wilson K, MacDougall L, Fergusson D, Graham I, Tinmouth A, Hébert PC. The effectiveness of interventions to reduce physician's levels of inappropriate transfusion: what can be learned from a systematic review of the literature. Transfusion. 2002;42:1224-1229.

8. Powell C. The Delphi technique: myths and realities. $J$ Adv Nurs. 2003;41(4):376-382.

9. Hallsworth M, Chadbom T, Sallis A et al. Provision of social norm feedback to high prescribers of antibiotics in general practice: a pragmatic national randomised controlled trial. Lancet. 2016;387(10029):1743-1752.

10. Friedman M, Arja W, Batra R et al. Informed consent for blood transfusion: what do medicine residents tell? What do patients understand? Am J Clin Pathol. 2012;138(4):559-565.

11. Mayo E. The Human Problems of an Industrial Civilization. New York: Macmillan Co.; 1933. 


\section{Supplementary material}

Indication for transfusion:

Acute uncontrollable bleeding?

Controllable bleeding

$\mathrm{Hb}<4.3 \mathrm{mmol} / \mathrm{L}$ and/or clinical symptoms of anemia in circulatory stable patient without heart disease.

Chest pain?

Orthostatic hypotension?

Tachycardia, not responding to fluid therapy?

Other? State here:

$\mathrm{Hb}<5.0 \mathrm{mmol} / \mathrm{L}$ and chronic heart disease and/or clinical symptoms of anemia in circulatory stable patient with chronic heart disease.

Chest pain?

Orthostatic hypotension?

Tachycardia, not responding to fluid therapy?

Other? State here:

$\mathrm{Hb}<5.6 \mathrm{mmol} / \mathrm{L}$ and concomitant

Acute coronary syndrome in ischemic phase?

Life threatening bleeding?

Other? State here:

Circulatory stable patient with heart disease and $\mathrm{Hb}$ between 5,0 and $5.6 \mathrm{mmol} / \mathrm{L}$ and ischemic symptoms. Which symptoms: ECG_ Chest pain__ Other

Has the patient been given information about the transfusion risks? Yes__ No

Figure SI Questionnaire on transfusion - translated version.

Abbreviation: $\mathrm{Hb}$, hemoglobin.

\section{Publish your work in this journal}

International Journal of Clinical Transfusion Medicine is an international, peer-reviewed, open access, online journal publishing clinicalexperimental, policy-making and evidence-based practices of all topics pertaining to clinical transfusion medicine. Original research, short reports, reviews, case reports and commentaries are invited
The manuscript management system is completely online and includes a very quick and fair peer-review system, which is all easy to use. Visit http://www.dovepress.com/testimonials.php to read real quotes from published authors.

Submit your manuscript here: https://www.dovepress.com/international-journal-of-clinical-transfusion-medicine-journal 